\title{
ARTIGO CIENTÍFICO \\ Simulação integrada dos recursos hídricos nos reservatórios Engenheiro Ávidos e São Gonçalo na Paraíba
}

\section{Integrated simulation of water resources of reservoirs Engenheiro Ávidos and São Gonçalo in Paraíba, Brazil}

\author{
Érika Lira da Silva', Allan Sarmento Vieira ${ }^{2}$
}

Resumo: Objetivou-se realizar uma simulação integrada nos reservatórios Engenheiro Ávidos e São Gonçalo, localizados, na Sub-bacia do Alto Piranhas no Estado da Paraíba, utilizando o modelo de rede de fluxo Acquanet. Utilizou-se o modelo tipo transformação chuva-vazão SMAP (Soil Moisture Accounting Procedure) para complementar a série de vazões naturais no período de 2010 a 2016. Assim a simulação realizada considerou uma série histórica de 1962 a 2016, com um cenário futuro onde foram adotados valores das demandas projetadas para o ano de 2032. Analisando a parte operacional dos reservatórios foi observado, no período simulado, que os mesmos atingiram seu volume máximo em muitos meses; na maioria dos períodos o volume meta foi respeitado; o volume mínimo foi atingido em alguns momentos devido aos baixos índices pluviométricos, fato que se intensificou nos últimos anos. Quanto às demandas, o abastecimento humano e dessedentação apresentaram confiabilidade acima dos $90 \%$, já para a irrigação e indústria, o número de falhas foi maior. No cenário futuro, os resultados tiveram uma representação diferente, em poucos momentos chegaram ao volume máximo, por muitos meses operaram no volume mínimo, não conseguindo atender ao requerimento operacional do volume meta, e consequentemente o atendimento às demandas também não foi satisfatório. As falhas ocorreram no abastecimento humano e animal nos dois reservatórios, onde a confiabilidade ficou acima de $70 \%$, e as demandas irrigação e indústria apresentaram um grande déficit de atendimento.

Palavras-chave: Água; Série histórica; Demanda hídrica

\begin{abstract}
The objective of this research is to perform an integrated simulation in the Engenheiro Ávidos and São Gonçalo reservoirs, located in the Upper Piranhas Sub-basin in the State of Paraíba, using the Acquanet flow network model. Use of the SMAP rain-flow transformation model to complement the series of natural discharges in the period from 2010 to 2016 . Thus, a simulation carried out considered a historical series from 1962 to 2016, with a future scenario Where values of the projected demands for the year 2032 were adopted. Analyzing an operational part of the reservoirs was observed, no simulated period, in which they are their maximum volume in many months; In most periods of the target volume was respected; The minimum volume is empty at times due to low rainfall levels, a fact that has intensified in recent years. Regarding the demands, the human supply and the water supply had reliability above $90 \%$, for irrigation and industry, the number of failures was higher. In the future scenario, the results provide a different representation, in a few moments for the maximum volume, for many months operated in the minimum volume, not able to meet the operational requirement of the target volume, and consequently the attendance to the demands was also not satisfactory. As failures occurred in human and animal supplies in the two reservoirs, where reliability was above $70 \%$, and as irrigation and industry requirements presented a large service deficit.
\end{abstract}

Key words: Water; Historic Serie; Water demand.

\footnotetext{
Trabalho apresentado no IV Encontro Interdisciplinar da Paraíba realizado entre 09 a 10 de novembro de 2017 no Centro de Ciências Jurídicas e Sociais da Universidade Federal de Campina Grande, Sousa, Paraíba.

*Autor para correspondência

Recebido para publicação em 12/11/2017; aprovado em 23/11/2017

${ }^{1}$ Administradora, Especialista em Gestão Ambiental, Universidade Federal de Campina Grande, Sousa, Paraíba; (83)99627-3519, erikaliradasilva@ gmail.com. ${ }^{2}$ Professor Doutor em Recursos Naturais , Grupo de Pesquisa Gestão Ambiental no Semiárido, Universidade Federal de Campina Grande , Sousa, Paraíba. (83) 3521-3236, allan.sarmento@ufcg.edu.br.
} 


\section{INTRODUÇÃO}

O Brasil é um país considerado rico em termos de disponibilidade hídrica, pois detém cerca de $12 \%$ da água doce do planeta. Apesar desse percentual ser tão significativo, o país apresenta uma ampla variação espacial e temporal das vazões. Por possuir um território muito extenso, apresenta clima e índices pluviométricos com grandes irregularidades. A precipitação média anual é de $1.797 \mathrm{~mm}$, com grandes variações, que vão desde menos de $800 \mathrm{~mm}$, como na região semiárida do Nordeste, a mais de $2.500 \mathrm{~mm}$, na região da Amazônia. As bacias hidrográficas localizadas em áreas com baixas precipitações e grande utilização dos recursos hídricos passam por grandes problemas de escassez e estresse hídrico (ANA, 2005). Embora a crise de água seja um problema atual e amplamente conhecido, um número cada vez maior de pessoas está vivendo em meio a um estresse hídrico, uma vez que a água continua a ser mal gerenciada, e não valorizada como deveria. $\mathrm{O}$ monitoramento adequado da quantidade e a qualidade dos recursos hídricos ainda continua sendo um grande desafio para muitos países, inclusive o Brasil, que precisa melhorar muito nesse sentido (UNSGAB, 2016).

Andrade (2006) relata que a modernização da gestão hídrica no Brasil só se tornou efetiva através da Política Nacional de Recursos Hídricos, que foi instituída por meio da Lei $\mathrm{n}^{\circ}$ 9.433, de 1997, mais conhecida como Lei das Águas, com o objetivo de tornar possível o grande desafio de garantir água em qualidade e quantidade adequadas para a sociedade, propiciar a utilização racional e integrada dos recursos hídricos, visando o desenvolvimento sustentável, e promover a prevenção e amparo em casos de eventos hidrológicos críticos, como inundações e estiagens.

A Lei Estadual $\mathrm{N}^{\circ}$ 6.308, de 02/07/1996, instituiu o Sistema Integrado de Planejamento e Gerenciamento de Recursos Hídricos (SIGERH), no Estado da Paraíba, com o objetivo de assegurar o uso integrado e racional dos recursos hídricos, em seu art. $5^{\circ}$ explica que essa lei tem como intuito a execução da Política Estadual de Recursos Hídricos, assim como é responsável por formar, atualizar e aplicar o Plano Estadual de Recursos Hídricos, em conformidade com os órgãos e entidades estaduais e municipais, e sociedade civil organizada.

Após cinco anos seguidos de poucas precipitações no Semiárido do Nordeste, a região continua em situação crítica em termos de disponibilidade hídrica, uma vez que os índices pluviométricos de 2015 e 2016 não foram suficientes para a reposição dos estoques de água, ocasionando uma grande redução no volume dos reservatórios, quando muitos chegaram a secar totalmente (ANA, 2016). O reservatório São Gonçalo, situado no município de Sousa na Paraíba, é um exemplo dessa situação de crise hídrica. O reservatório de Engenheiro Ávidos, no município de Cajazeiras, que tem capacidade máxima de $255.000 .000 \mathrm{~m}^{3}$ de água, vem sofrendo uma grande queda nos últimos 5 anos, operando atualmente com aproximadamente $13.000 .000 \mathrm{~m}^{3}$, ou seja, cerca de $5,1 \%$ de sua capacidade (AESA, 2017).

No sentido de colaborar com o planejamento e gerenciamento dos recursos hídricos, estudos fazem uso dos métodos de simulação e otimização, através do ACQUANET. No estudo realizado por Maia (2006), foi analisada a interferência da variação do volume útil do reservatório de Promissão, no Médio Tietê, em São Paulo, na geração de energia elétrica em uma usina hidrelétrica, no qual foi utilizado o modelo ACQUANET. Feitosa (2013) utilizou o ACQUANET na simulação da operação do reservatório de Santa Cruz em Apodi, Rio Grande do Norte, de acordo com os múltiplos usos da água, e a limitação na disponibilidade hídrica do reservatório.

Os modelos de simulação podem permitir uma representação matemática bastante detalhada e realística do sistema, devido às equações geradas a partir das varáveis analisadas, e por isso possibilita ao tomador de decisão observar o desempenho do sistema considerando os diversos cenários e regras de operação, que podem ser modificadas até que os resultados se aproximem do considerado como ótimo, já os modelos de otimização são representados por uma fórmula matemática onde um algoritmo é utilizado para o cálculo de um conjunto de variáveis de decisão que minimizem ou maximizem a função objetivo, observadas as restrições existentes. Esse método traz a solução para a escolha da alternativa ótima, que maximize o índice de eficiência desejado (VIEIRA, 2011; SANTOS, 2011).

Como Sistema de Suporte à Decisão (SSD), o ACQUANET apresenta-se como um modelo muito útil em estudos de recursos hídricos. De acordo com Maia (2006), o ACQUANET é um modelo de rede de fluxo para simulação de bacias hidrográficas, desenvolvido pelo Laboratório de Sistemas de Suporte a Decisões em Engenharia Ambiental e de Recursos Hídricos, o LabSid. Foi desenvolvido com objetivo de auxiliar os tomadores de decisão no gerenciamento de bacias hidrográficas, no qual o usuário possui ferramentas para montar redes com vários reservatórios, demandas e trechos de canais, possibilitando a representação mais detalhada e realista do sistema em estudo (ACQUANET 2013).

Para tornar possível o atendimento às necessidades hídricas de forma eficiente, é necessário o gerenciamento adequado dos recursos hídricos. Nesse sentido, as pesquisas nessa área são indispensáveis, através da utilização de ferramentas que auxiliem no processo de tomada de decisões, a exemplo dos modelos matemáticos. Estes são de grande valia para a um planejamento e gerenciamento preciso acerca das questões que envolvem os múltiplos usos da água. Através da aplicação de modelos matemáticos é possível analisar a situação das bacias hidrográficas, pode-se também identificar um cenário ótimo ou ideal de alocação de água para cada tipo de demanda, realizar simulações com diferentes situações de disponibilidade hídrica, e assim possibilitar um gerenciamento eficiente dos recursos hídricos. São exemplos de modelos matemáticos muito utilizados em pesquisas os métodos de simulação e otimização.

Dessa maneira é possível simular cenários com situações que podem vir a ocorrer, seja de cheia ou de seca, da priorização de um setor ao racionamento em outro, no intuito de auxiliar os gestores na tomada de decisão mais adequada para cada situação e cenário possíveis, evitando decisões errôneas que possam trazer prejuízos a todas as partes interessadas e a população em geral. Pensar na gestão integrada para controle dos recursos hídricos é se adequar a uma realidade há muitos anos evidente, porém muitas vezes não planejada. A seca existe no semiárido existe e sempre existirá, mas cabe a uma gestão eficiente e integrada com todas as partes interessadas, saber lidar com os recursos que esse ambiente proporciona, e utilizá-los da melhor forma possível. 
Diante desse contexto, objetivou-se analisar o comportamento hídrico dos reservatório Engenheiro Ávidos e São Gonçalo, ambos localizados na Sub-bacia do AltoPiranhas no Estado da Paraíba, com base nos métodos de simulação e otimização dispostos no modelo ACQUANET.

\section{MATERIAL E MÉTODOS}

A pesquisa utilizou o método dedutivo, quanto aos fins, vem a ser considerada como explicativa, e em relação aos procedimentos utilizados, este estudo pode ser caracterizado como bibliográfico e estudo de caso. A pesquisa está voltada para os reservatórios Engenheiro Ávidos e São Gonçalo, localizados no interior do Sertão paraibano, situados na Região do Alto Curso do Rio Piranhas. "Esta Sub-bacia situase na região sudoeste do Estado da Paraíba, no Nordeste do Brasil, entre as coordenadas geográficas de 6o 50' e 7o 25' de latitude sul e 380 10' e 38 o 40' de longitude a oeste de Greenwich" (FARIAS, 2004 p. 14).

De acordo com o Plano de Recursos Hídricos da Bacia hidrográfica dos rios Piancó-Piranhas-Açu (2016), a bacia hidrográfica dos rios Piancó-Piranhas-Açu é a maior da Região Hidrográfica Atlântico Nordeste Oriental, ocupando uma área total de $43.683 \mathrm{~km}^{2}$. Está inserida em território de clima semiárido, e por suas características naturais, apresenta chuvas irregulares, concentradas em poucos meses do ano, caracterizado por períodos alternados de pluviosidade regular e anos consecutivos de baixos índices pluviométricos, que resultam em longos períodos de estiagem, causando baixa disponibilidade hídricos nos reservatórios.

O reservatório Engenheiro Ávidos, juntamente com Engenheiro Armando Ribeiro Gonçalves, no Rio Grande do Norte, o Curema/Mãe d'Água e, na Paraíba, correspondem a cerca de $70 \%$ da capacidade de armazenamento da bacia. Esses reservatórios são responsáveis pela perenização de trechos de rio, nos quais se desenvolvem diversos usos da água, onde podemos ressaltar a grande importância para o abastecimento humano e a irrigação (AESA, 2016). Na figura 1 observa-se a localização da Região do Alto Piranhas, dentro do estado da Paraíba, com destaque para os reservatórios Engenheiro Ávidos e São Gonçalo, indicados pelas setas vermelhas.

Figura 1. Bacia do Alto Piranhas no Estado da Paraíba, Brasil

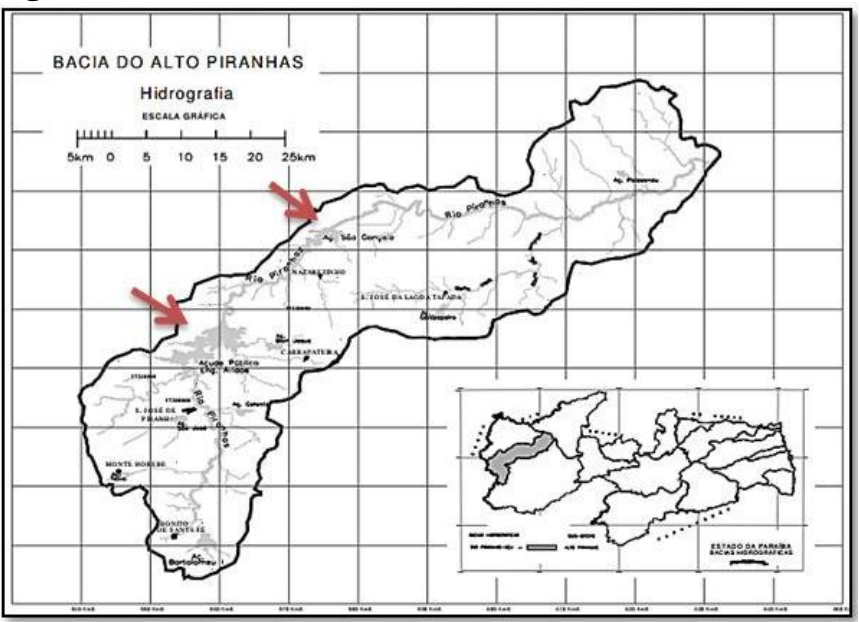

Fonte: FARIAS (2004)

Segundo o Plano Diretor da Bacia Piranhas-Açu (2014), deve-se considerar, para fins de planejamento e gerenciamento, o açude Engenheiro Ávidos e o São Gonçalo como reservatórios integrados. Os reservatórios em série Engenheiro Ávidos e São Gonçalo, representam a principal reserva hídrica superficial da bacia do Alto Piranhas, tendo uma distancia de $27 \mathrm{~km}$ entre eles. Segundo o Plano de Recursos Hídricos da Bacia hidrográfica dos rios PiancóPiranhas-Açu (2016), os açudes Engenheiro Ávidos e São Gonçalo apresentam uma forte dependência, para o atendimento das demandas totais, há uma total dependência do açude Engenheiro Ávidos. O reservatório São Gonçalo tem capacidade máxima de $44.600 .000 \mathrm{~m}^{3}$ de água, mas, neste ano de 2017, opera com apenas $12.000 .000 \mathrm{~m}^{3}$, ou seja, aproximadamente $27 \%$ de sua capacidade total, de acordo com dados do monitoramento da AESA- Agência Executiva de Gestão das Águas do Estado da Paraíba, (2017). Isso vem ocorrendo devido aos períodos de estiagem que a região enfrenta há alguns anos. Os recursos hídricos limitados e a irregularidade dos períodos chuvosos mostra a importância da destinação e uso eficiente da água, levando em consideração períodos de incertezas.

De acordo com Farias (2004), o reservatório Engenheiro Ávidos está localizado no município de Cajazeiras, Paraíba e tem como finalidade o abastecimento público da cidade de Cajazeiras e distrito de Engenheiro Ávidos, além da regularização do rio Piranhas. Esse reservatório é um dos principais componentes da Bacia do Alto Piranhas, porém, devido aos períodos de baixa estiagem seu volume hídrico vem apresentando grande decréscimo.

Foi utilizada a versão SMAP.Net, versão Windows (1.0.0.0 de 24/06/2015), disponível no site do LabSid, sendo aplicada a opção mensal do modelo. Para o cálculo das vazões naturais mensais dos anos de 2010 a 2016 através do modelo SMAP, foram necessários dados pluviométricos, dados evapotranspiração e vazões naturais médias, e dados gerais da área de estudo, denominados "dados inicias", como a área de drenagem (Ad), taxa de umidade (Tu), escoamento de base $(\mathrm{Eb})$, capacidade de campo $(\mathrm{Cc})$ e Abstração inicial (Ai), além da utilização de parâmetros específicos para a região em que se encontra a área de estudo (Tabela 1).

Tabela 1. Dados iniciais dos reservatórios Engenheiro Ávidos e São Gonçalo para modelo SMAP

\begin{tabular}{cccccc}
\hline \multirow{2}{*}{ Reservatório } & $\begin{array}{c}\text { Ád } \\
\left(\mathrm{km}^{2}\right)\end{array}$ & $\begin{array}{c}\mathrm{Tu} \\
(\%)\end{array}$ & $\begin{array}{c}\mathrm{Eb} \\
\left(\mathrm{m}^{3} / \mathrm{s}\right)\end{array}$ & $\begin{array}{c}\mathrm{Ai} \\
(\mathrm{mm})\end{array}$ & $\begin{array}{c}\mathrm{CC} \\
(\%)\end{array}$ \\
\hline $\begin{array}{c}\text { Engenheiro } \\
\text { Ávidos } \\
\text { São Gonçalo }\end{array}$ & $\begin{array}{l}92,11 \\
\text { 306,13 }\end{array}$ & 0 & 2,15 & 4 & 50 \\
\hline
\end{tabular}

Ad: área de drenagem; Tu: taxa de umidade; Eb: escoamento de base; Cc: capacidade de campo; Ai: Abstração inicial

Os parâmetros utilizados na aplicação do modelo foram os dispostos no Plano de Recursos Hídricos da Bacia Hidrográfica do rio Piancó-Piranhas-Açu (2016), ajustados a estação do Sítio Vassouras, aplicados para o período que compreende janeiro de 1994 a dezembro de 2007. Os parâmetros utilizados foram: Capacidade de saturação do solo (Sat); coeficiente de recarga do aquífero (Crec); taxa de geração de escoamento superficial (Pes); taxa de depleção do nível da água do aquífero subterrâneo (k) (Tabela 2). 
Tabela 2. Parâmetros dispostos no Plano de Recursos Hídricos da Bacia Hidrográfica do rio Piancó-Piranhas-Açu utilizados no modelo SMAP

\begin{tabular}{cccccc}
\hline Estação & Período & \multicolumn{4}{c}{ Parâmetros } \\
\hline $\begin{array}{c}\text { Sítio } \\
\text { Vassouras }\end{array}$ & Jan/94 a & $\begin{array}{c}\text { Sat } \\
\text { dez/2007 }\end{array}$ & $\begin{array}{c}\text { (mm) } \\
900\end{array}$ & $\begin{array}{c}\text { Pes } \\
\text { CREC }\end{array}$ & kkt \\
& & 90,8 & 1
\end{tabular}

Sat: Capacidade de saturação do solo; Crec: coeficiente de recarga do aquífero; Pes: taxa de geração de escoamento superficial; kkt: taxa de depleção do nível da água do aquífero subterrâneo

Fonte: (Adaptado do PRHBH Rio Piancó-Piranhas-Açu, 2016).

O modelo de rede fluxo hidrológico Acquanet necessitou do desenho da topografia do sistema hídrico estudado. Os dados de entrada necessários foram: demandas, séries de vazões naturais, cota $x$ área $x$ volume, volumes máximo e mínimo, volume meta, e evaporação média mensal (Tabela 3 e 4 ).

Destaca-se o fato da vazão de retirada do reservatório São Gonçalo apresentar um valor bem mais alto em relação ao Engenheiro Ávidos em virtude da existência do perímetro irrigado São Gonçalo (Tabela 4).

Tabela 3. Vazões de retirada por demanda dos reservatórios Engenheiro Ávidos e São Gonçalo, Paraíba, Brasil

\begin{tabular}{cccccc}
\hline \multicolumn{5}{c}{ Demandas Máximas $\left(\mathrm{m}^{3} / \mathrm{s}\right)$} \\
\hline $\begin{array}{c}\text { Abast. } \\
\text { Humano }\end{array}$ & $\begin{array}{c}\text { Dessed. } \\
\text { Animal }\end{array}$ & Irrigação & Indústria & Total \\
$\begin{array}{c}\text { Engenheiro } \\
\text { Avidos } \\
\text { São } \\
\text { Gonçalo } \\
\quad \text { Nível }\end{array}$ & 0,179 & 0,016 & 0,117 & 0,021 & 0,333 \\
Prioridade & 1 & 1 & 2 & 3 & - \\
\hline Fonte: (Adaptado do PRHBH Rio Piancó-Piranhas-Açu, 2016) & & & & & \\
\end{tabular}

Tabela 4. Volumes dos reservatórios Engenheiro Ávidos e São Gonçalo, Paraíba, Brasil

\begin{tabular}{cccc}
\hline DADOS & $(\%)$ & $\begin{array}{c}\text { Engenheiro } \\
\text { Ávidos }\end{array}$ & $\begin{array}{c}\text { São } \\
\text { Gonçalo }\end{array}$ \\
\hline Vol. Máximo $\left(\mathrm{m}^{3}\right)$ & 100 & 255.000 .000 & 44.600 .000 \\
Vol. Mínimo $\left(\mathrm{m}^{3}\right)$ & 11 & 27.968 .100 & 2.982 .000 \\
Vol. Meta $\left(\mathrm{m}^{3}\right)$ & 15 & 38.250 .000 & 6.690 .000 \\
\hline
\end{tabular}

confiabilidade (Conf) é a probabilidade da série temporal permanecer em estado satisfatório durante o horizonte de operação, ou seja, a percentagem do tempo em que o sistema funciona sem falhas". A confiabilidade foi calculada conforma a equação 1 .

Conf $=[1-(\mathrm{NF} / \mathrm{NT})] \times 100$

(Eq. 1)

Em que: $N F$ éo número total de falhas encontradas no intervalo de tempo; NT é o número total de intervalos de tempo simulados.

$\mathrm{O}$ valor de confiabilidade calculado foi informado em forma percentual para as demandas dos dois reservatórios, tanto para a simulação da série histórica quanto para o cenário futuro.

As simulações foram realizadas com o modelo SMAP, a fim da obtenção dos valores de vazões naturais mensais de 2010 a 2016. Esses valores foram empregados no modelo Acquanet, juntamente com os demais dados, o qual executou o cálculo utilizando 55 anos, no período compreendido entre janeiro de 1962 a dezembro de 2016.
Para o cenário proposto, o horizonte de simulação vislumbrou o ano de 2032, conforme as demandas previstas no PRH Rio Piancó-Piranhas-Açu (2016), que traz os valores indicados para cada demanda, englobando abastecimento humano, dessedentação animal, irrigação e indústria. Esses valores de retirada observa-se na Tabela 5, e são mais altos que os atuais, que é a tendência ao longo dos anos, o aumento na necessidade da demanda.

Tabela 5. Demandas projetadas para 2032 dos reservatórios Engenheiro Ávidos e São Gonçalo, Paraíba, Brasil

\begin{tabular}{ccccc}
\hline Reservatório & $\begin{array}{c}\text { Abast. } \\
\text { Humano }\end{array}$ & $\begin{array}{c}\text { Dessed. } \\
\text { animal }\end{array}$ & Irrigação & Indústria \\
\hline $\begin{array}{c}\text { Engenheiro } \\
\text { Ávidos }\end{array}$ & 0,192 & 0,035 & 0,195 & 0,042 \\
São Gonçalo & 0,186 & 0,009 & 4,248 & 0,074 \\
\hline
\end{tabular}

Fonte: PRHBH Rio Piancó-Piranhas-Açu, 2016

A projeção das demandas foi realizada, de acordo com o texto contido no PRHBH Rio Piancó-Piranhas-Açu (2016) "As demandas futuras de água foram estimadas a partir da análise dos padrões de crescimento demográfico e de setores econômicos observados nos últimos 10 anos na bacia". Dessa forma, os índices de crescimento aplicados às demandas de água no cenário atual possibilitaram o estabelecimento das projeções futuras para cada reservatório.

\section{RESULTADOS E DISCUSSÃO}

Para o comparativo dos meses simulados e da série histórica (Figuras 2 e 3 ) observa-se o comportamento das vazões ao longo de todo o período estudado nos reservatórios Engenheiro Âvidos e São Gonçalo, incluindo as vazões naturais calculadas neste estudo, determinadas pelo modelo chuva-vazão SMAP, destacadas pelas setas vermelhas.

Figura 2. Vazões naturais reservatório Engenheiro Ávidos, Paraíba, Brasil

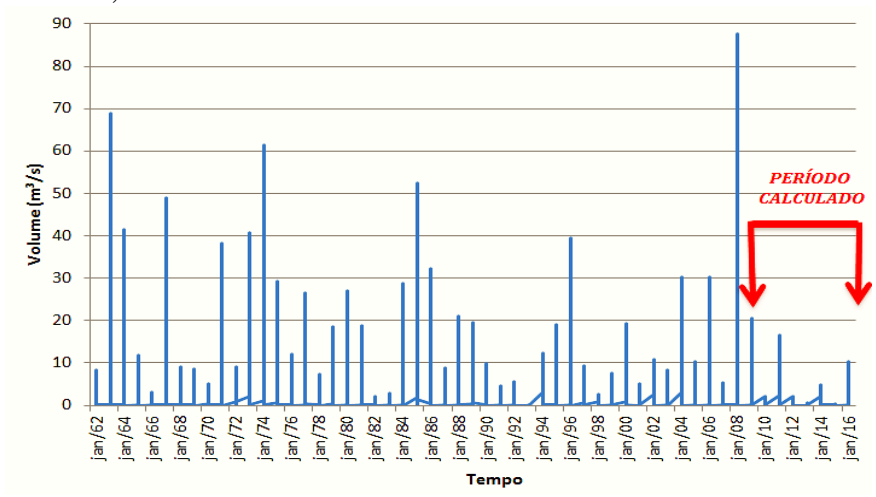

Figura 3. Vazões naturais reservatório São Gonçalo, Paraíba, Brasil

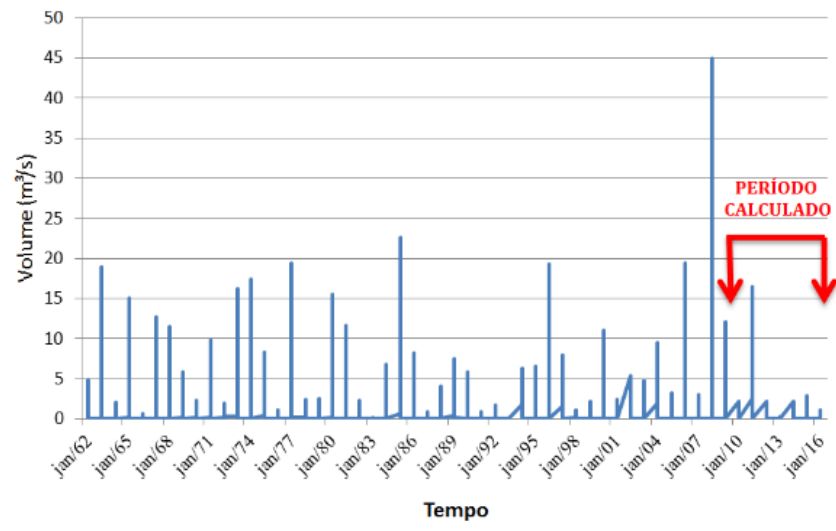

Revista Verde, v.12, n.5, p.892-901, 2017 
No período simulado ocorreram anos consecutivos de estiagem, com poucas precipitações, o que ocasionou vazões naturais mais baixas para o reservatório Engenheiro Ávidos, causando grande impacto em seu volume armazenado.

$\mathrm{Na}$ simulação com série histórica de 1962 a 2016, analisando o desempenho dos dois reservatórios e ao fornecimento de água para as necessidades das demandas.

Na Figura 4 nota-se o layout, ou seja, o traçado da topografia do sistema analisado, o qual foi desenhado com o uso das ferramentas disponíveis no ACQUANET.

Figura 4. Layout do sistema Engenheiro Ávidos-São Gonçalo, Paraíba, Brasil

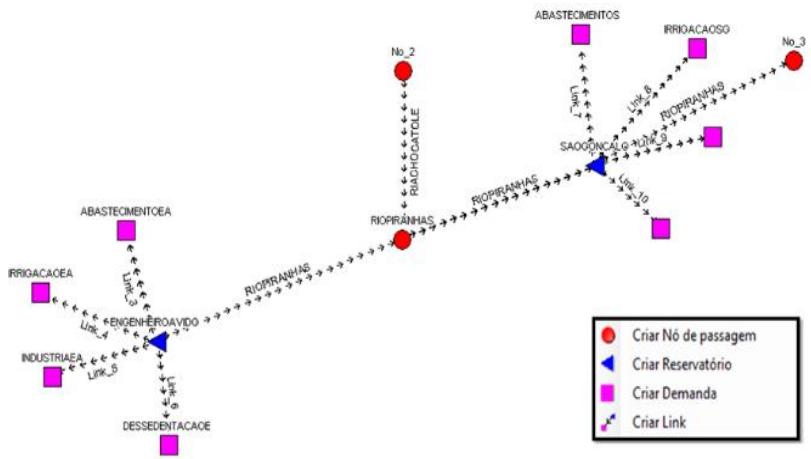

Esse traçado ilustra o percurso hídrico, como funciona a dinâmica dos reservatórios e rio envolvidos, assim como a retirada das demandas de cada reservatório.

\section{Reservatório Engenheiro Ávidos}

No início da série, foi estabelecido o volume inicial do reservatório com $50 \%$ de sua capacidade máxima. O volume meta empregado nesta pesquisa foi de $15 \%$, assumindo seu volume mínimo como $10 \%$ (Figura 5).

Figura 5. Comportamento do volume armazenado do reservatório Engenheiro Ávidos, Paraíba, Brasil

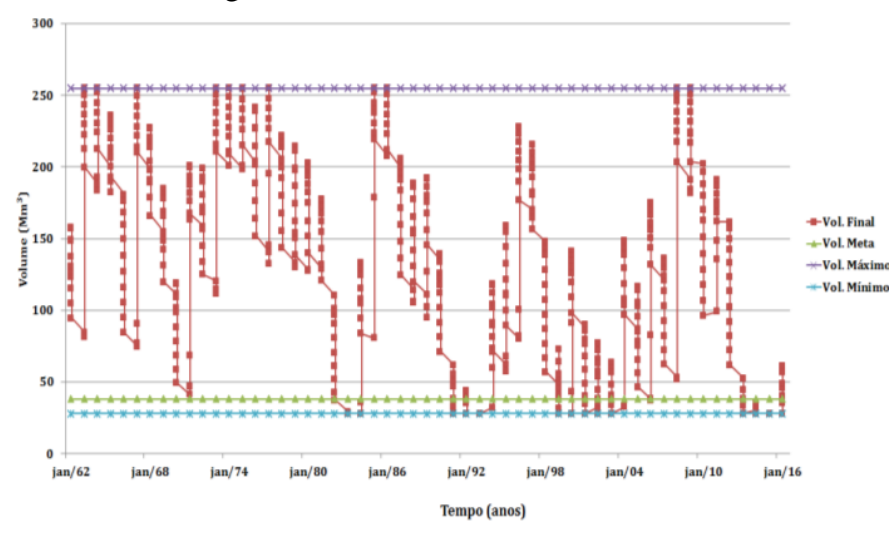

Nota-se uma grande variabilidade no volume, caracterizado pelos anos alternados de altos índices pluviométricos e de períodos de estiagem, que é uma característica da região em que está inserido. Entre os anos de 1963 a 1978 houve muitos episódios onde o volume máximo foi atingido, mantendo-se sempre acima do volume meta. Em contrapartida, a partir do ano 1982, iniciaram-se períodos de volumes mais baixos, chegando a atingir seu volume mínimo em vários anos.

Entre 1999 e 2004 é possível perceber que o reservatório operou com sua capacidade mínima, fato que tornou a ocorrer de forma mais acentuada nos anos mais recentes, de 2012 a 2016, em que as vazões naturais não foram suficientes para que Engenheiro Ávidos tivesse aumento em seu volume, o que afeta diretamente as demandas envolvidas. É importante ainda ressaltar que para essa representação gráfica o modelo não reconheceu o vertimento no reservatório em nenhum mês, mesmo em meses que houve vazões suficientes. $\mathrm{O}$ modelo então converte esses vertimentos em vazões para o link que representa o trecho do Rio Piranhas.

A demanda para abastecimento humano, um uso prioritário segundo a lei 9.433/97, é um relevante aspecto na análise de desempenho do reservatório (Figura 6).

Figura 6. Retiradas para o abastecimento no reservatório Engenheiro Ávidos, Paraíba, Brasil

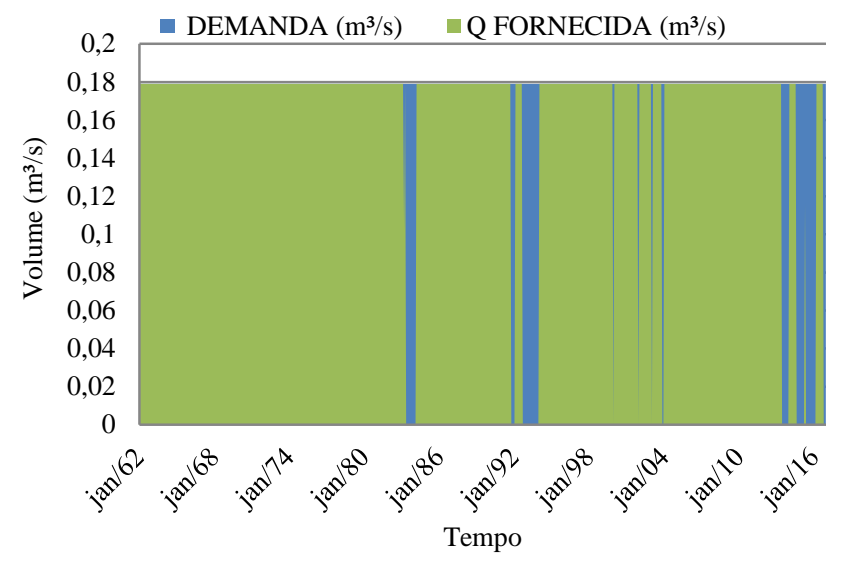

Observa-se na figura 6, que a demanda hídrica para abastecimento foi atendida plenamente até o ano 1983, porém, as falhas se iniciaram a partir desse ano, se mantendo, mesmo de forma alternada, mais constantes, ou seja, houve déficit no atendimento, principalmente nos últimos anos, onde o problema tem se agravado em função dos últimos 5 anos de baixos índices pluviométricos. É importante ressaltar que além dos períodos de baixas chuvas, as demandas tendem a aumentar ao longo dos anos, ocasionando maior retirada e menor volume água acumulada no reservatório. O cálculo da confiabilidade para esta demanda foi de $90,30 \%$, com uma frequência de $9,85 \%$ abaixo da demanda necessária.

No atendimento a demanda relativa ao uso hídrico para dessedentação de animais (Figura 7).

Figura 7. Retiradas para dessedentação de animais no reservatório Engenheiro Ávidos, Paraíba, Brasil

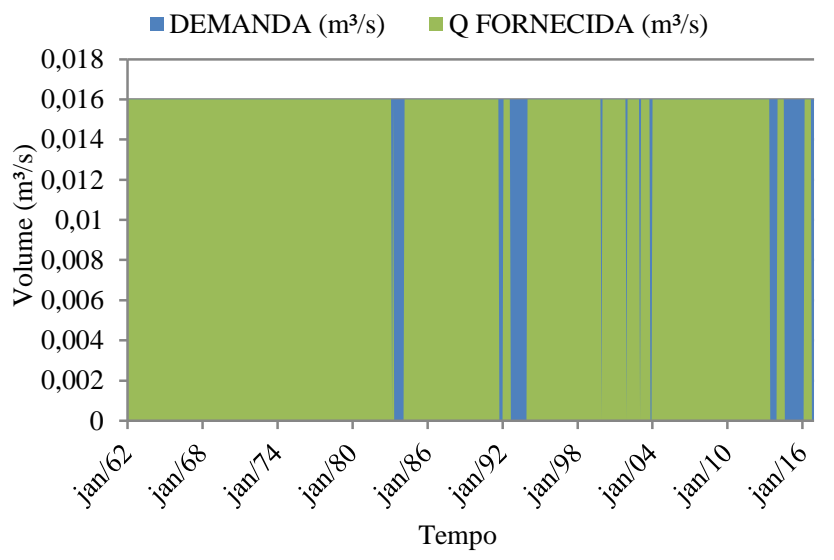


É possível verificar que, apesar dos períodos em que a demanda foi atendida com êxito, também apareceram falhas, que se intensificaram em virtude dos períodos mais ocorrentes de poucas chuvas. A confiabilidade de atendimento foi de $90,15 \%$. Em relação à demanda industrial, na Figura 8 observa-se os resultados do atendimento aos valores de retirada no reservatório Engenheiro Ávidos.

Figura 8. Retiradas para indústria no reservatório Engenheiro Ávidos, Paraíba, Brasil

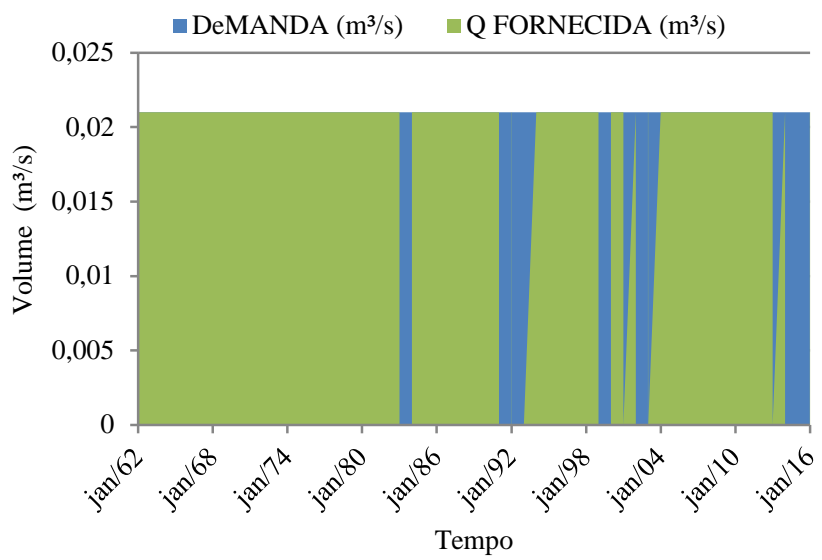

As quantidades retiradas foram suficientes para as necessidades dessa demanda na maioria dos anos, com intervalos de falha em alguns períodos, que se mostraram maiores entre 1991 e 1992, e 2012 a 2016. O percentual de confiabilidade para essa demanda é foi de $88,18 \%$, e um frequência de $11,97 \%$ abaixo da demanda necessária, por ter o nível de prioridade mais inferior as demais demandas. Já a irrigação, a demanda que consome mais água, tendo um valor de retirada bem mais alto que os demais usos (Figura 9). O percentual de confiabilidade calculada corresponde a $89,85 \%$.

Figura 9. Retiradas para irrigação no reservatório Engenheiro Ávidos, Paraíba, Brasil

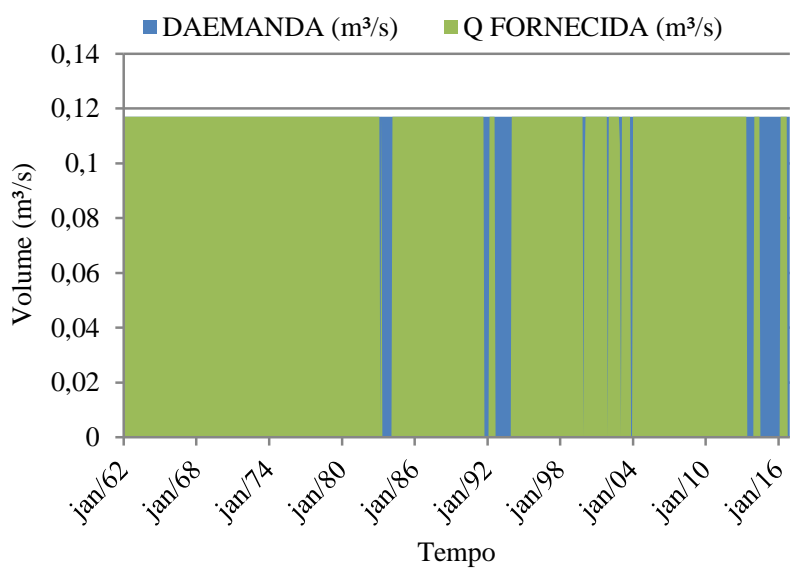

As demandas tiveram plena satisfação, porém, a partir de 1983, iniciaram-se as falhas, tornando-se mais frequentes, e comprometendo a atividade da agricultura irrigada, responsável pela geração de renda para muitas famílias e para o município. Em virtude do déficit para a irrigação, que ainda ocorre através de métodos que não possuem muita tecnologia, e consequentemente consomem mais água, essa atividade deve ser bem planejada e buscar meios mais econômicos.

\section{Resultados Reservatório São Gonçalo}

$\mathrm{Na}$ simulação realizada para a série histórica no reservatório São Gonçalo, foi adotado, assim como para Engenheiro Ávidos, um volume meta de $15 \%$ de sua capacidade máxima, e um volume mínimo de $10 \%$, para atendimento das demandas. Na figura 10 observa-se a constância de altos volumes no reservatório nos anos iniciais até 1982, em que o volume meta foi cumprido em todos os anos. Mas verifica-se que a partir desse ponto, ocorreram períodos de baixos volumes, chegando ao limite do volume mínimo. A constância dos períodos secos também é um ponto a ser ressaltado, intensificando o descumprimento do volume meta em vários anos, o que trouxe transtornos e falta de água para a população e todas as demandas envolvidas.

Figura 10. Comportamento do volume armazenado do reservatório São Gonçalo, Paraíba, Brasil

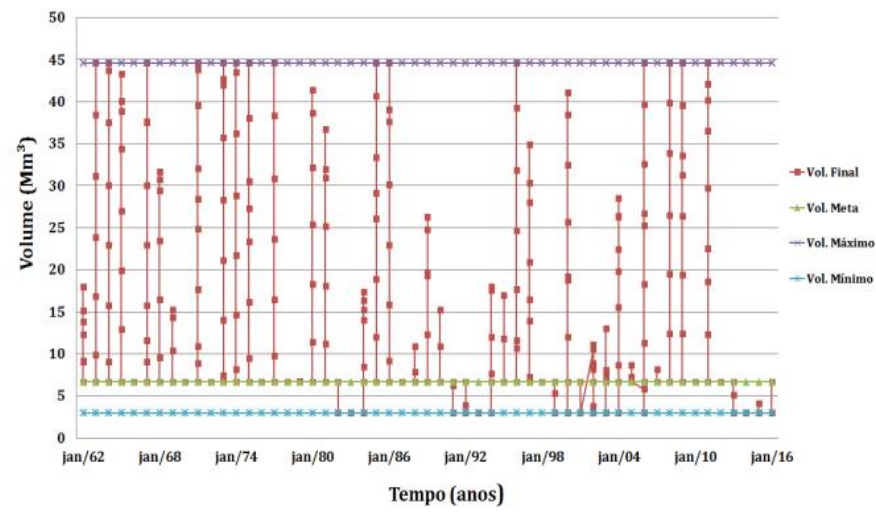

Quanto ao desempenho do reservatório, em sua maioria apresentou resultado satisfatório, porém ressalta-se que o provável aumento do consumo hídrico das demandas traz mais possibilidades de déficit de disponibilidade para este reservatório. É importante frisar, a respeito dos resultados fornecidos pelo modelo, que este não reconheceu valores abaixo do volume mínimo, que provavelmente ocorreram, mas que não foram representados na simulação obtida. As retiradas de água para a demanda de abastecimento são observadas na Figura 11.

Figura 11. Retiradas para abastecimento no reservatório São Gonçalo, Paraíba, Brasil

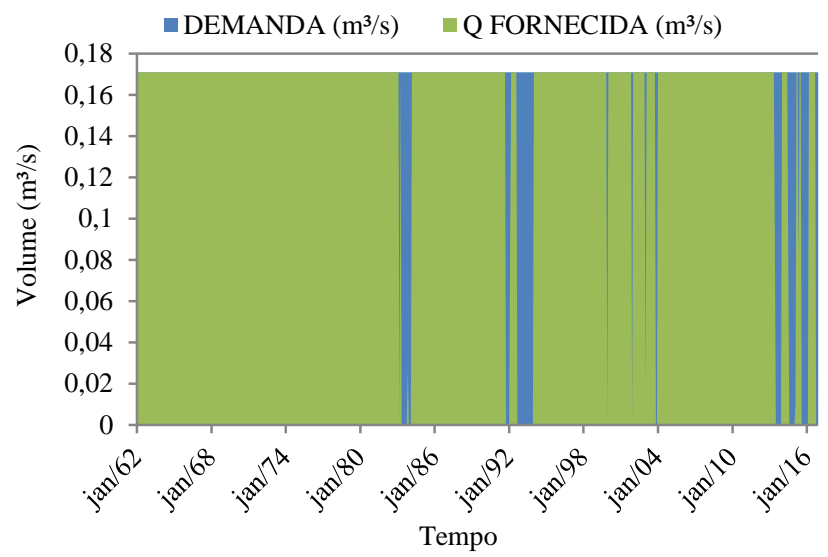


O que se pode observar é que houve períodos em que a demanda foi totalmente atendida, períodos estes que são maioria, mas também apresentou muitas falhas no atendimento, que se acentuaram a partir de 2013. O cálculo da confiabilidade de atendimento para abastecimento foi de 90,91\%. Em virtude dos períodos secos, o reservatório não conseguiu atender de forma satisfatória em todos os meses. Já para as retiradas destinadas a dessedentação animal, as falhas também foram observadas em diferentes anos, como mostra a Figura 12 abaixo.

Figura 12. Retiradas para dessedentação animal no reservatório São Gonçalo, Paraíba, Brasil

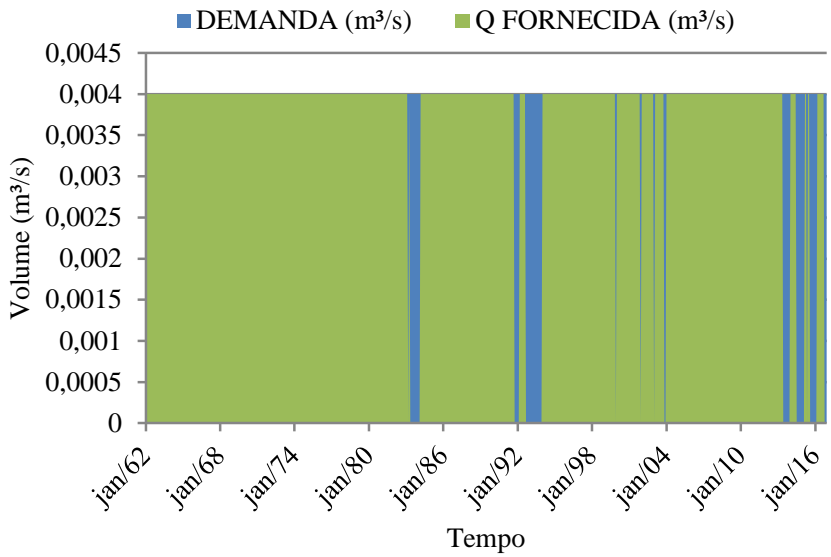

As falhas ocorreram em períodos de baixa pluviosidade, como observados na figura 4.2.3, que representa desempenho do reservatório ao longo dos anos, impedindo que a quantidade fornecida suprisse a necessidade da demanda. A confiabilidade para esta demanda foi de $90,45 \%$. Em relação à retirada para demanda industrial, a Figura 13 ilustra o comportamento das retiradas d'água para essa finalidade.

Figura 13. Retiradas para indústria no reservatório São Gonçalo, Paraíba, Brasil

- DEMANDA $\left(\mathrm{m}^{3} / \mathrm{s}\right) \quad \mathrm{Q}$ FORNECIDA $\left(\mathrm{m}^{3} / \mathrm{s}\right)$

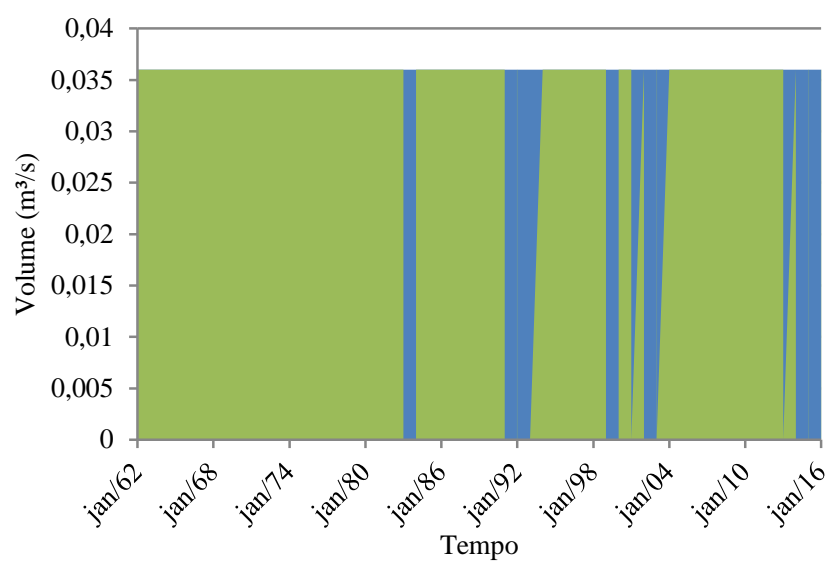

A confiabilidade para a demanda industrial foi calculada em $88,18 \%$, já que apresentou falhas em alguns pontos, mas que em sua maioria na série analisada, a demanda para indústria foi atendida devidamente.

As culturas irrigadas possuem uma característica muito marcante nessa região, onde está presente o Perímetro irrigado São Gonçalo, responsável pela produção em larga escala de culturas como o coco. A produção está concentrada no distrito de São Gonçalo, em Sousa-PB. Em relação à demanda hídrica destinada a essa atividade, a figura 14 demonstra as informações importantes a serem analisadas.

Figura 14. Retiradas para irrigação no reservatório São Gonçalo, Paraíba, Brasil

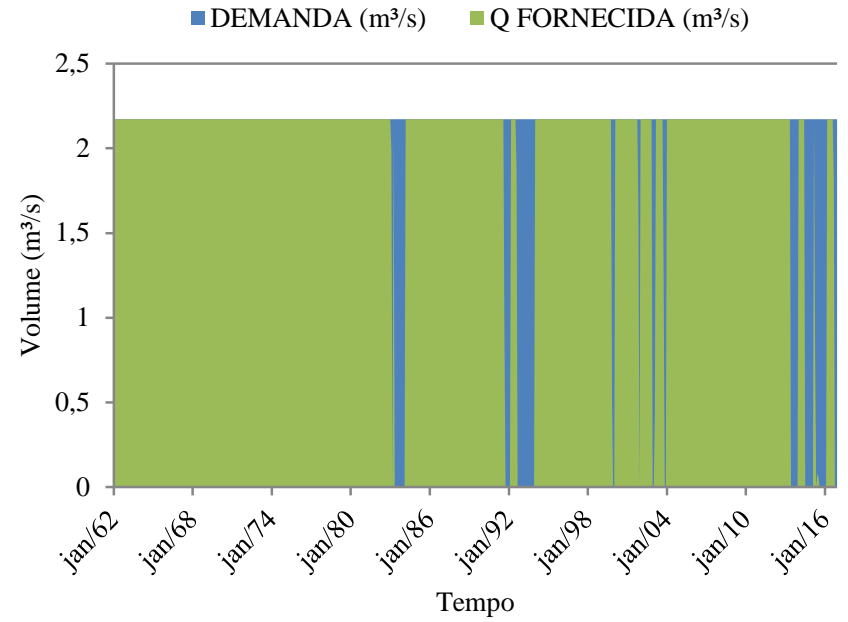

Com um consumo bastante considerável nesse reservatório, a irrigação é responsável por grande retirada de volume de São Gonçalo. De acordo com os resultados da simulação, o atendimento apresentou falhas. As retiradas d'água para a irrigação de culturas não foram suficientes em todo o período simulado, o para a economia local causa um grande impacto, e a confiabilidade calculada foi $89,24 \%$.

\section{Simulações cenário futuro}

\section{Reservatório Engenheiro Ávidos}

O reservatório Engenheiro Ávidos apresentou como resultado da simulação, o comportamento ilustrado na Figura 15. Com o aumento na parcela retirada para as demandas, o comportamento do reservatório apresentou diferenças significantes. Já no início do período simulado, o volume esteve abaixo do volume meta, chegando ao volume mínimo, diferente da primeira simulação, com a demanda atual, onde havia iniciado a série com volume bem acima do volume meta estabelecido, onde também chegou a seu volume máximo em muitos meses.

Figura 15. Comportamento do volume armazenado do reservatório Engenheiro Ávidos, Paraíba, Brasil

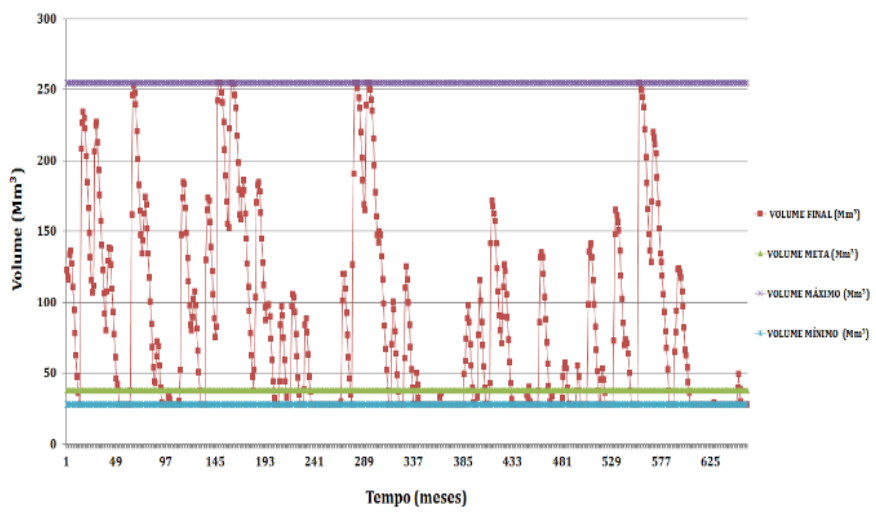

Em todo o período apresentou muitos episódios de volume abaixo do recomendado, ao contrário do que foi visto na primeira simulação, onde a maioria dos anos havia um 
volume suficiente. $\mathrm{O}$ reservatório, com as demandas estipuladas futuramente, traz complicações operacionais, atuando com seu volume mínimo e trazendo restrições ao atendimento pleno das demandas, que são mais detalhadas a seguir.

Para as retiradas de água referentes ao abastecimento, para este novo cenário, as falhas observadas se tronaram bem mais acentuadas.

Figura 16. Retiradas para o abastecimento no reservatório Engenheiro Ávidos, Paraíba, Brasil

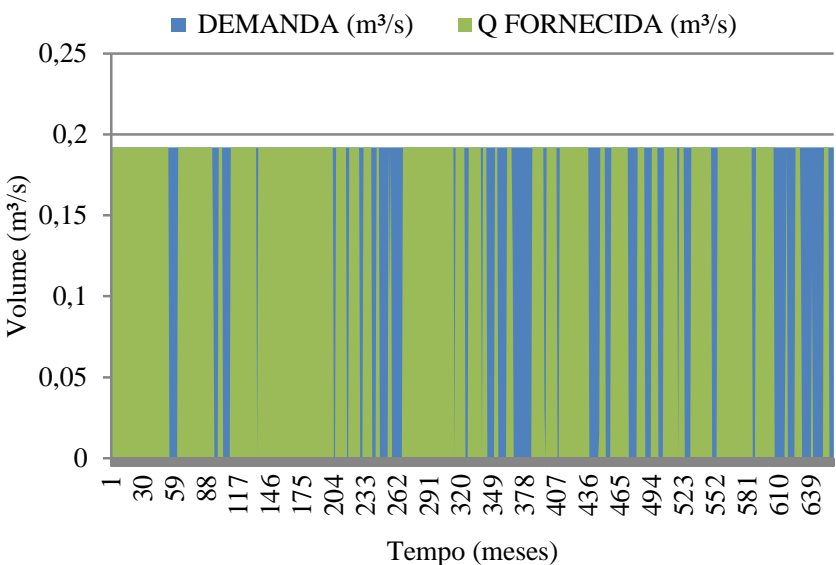

É possível observar o grande aumento dos déficits em relação a serie histórica anteriormente analisada, o que mostra a ineficiência para atendimento dessa demanda, quando aumentada a parcela retirada do reservatório. A confiabilidade calculada para atendimento da demanda abastecimento, com o valor de $73,64 \%$, evidencia a queda na capacidade de fornecimento de água do reservatório, que na simulação anterior, era de $90,30 \%$.

De forma semelhante, a demanda destinada dessedentação animal também apresentou relevante aumento nas falhas de atendimento. Já a confiabilidade de atendimento calculada foi $71,67 \%$.

Figura 17. Retiradas para dessedentação animal no reservatório Engenheiro Ávidos, Paraíba, Brasil

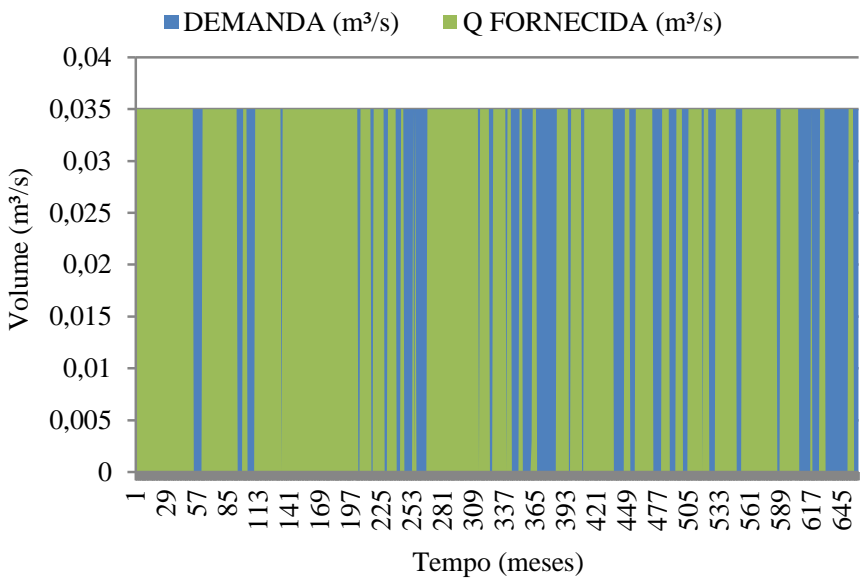

As retiradas destinadas ao uso industrial apresentaram um número bem mais amplo de falhas no atendimento, que podem ser visualizados claramente na Figura 18. A dificuldade se acentua, já que as outras demandas foram priorizadas, a confiabilidade para essa demanda se mostra inferior às demais, correspondendo a $62.72 \%$
Figura 18. Retiradas para indústria no reservatório Engenheiro Ávidos, Paraíba, Brasil

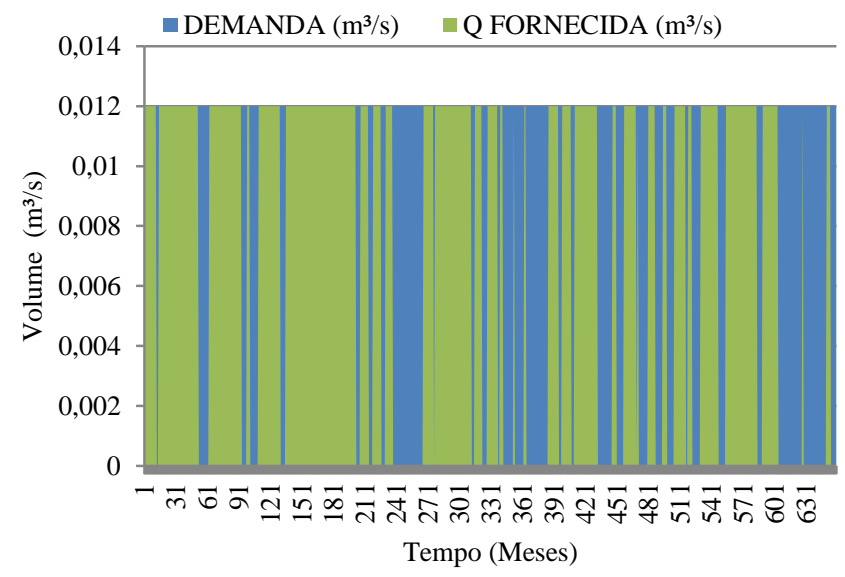

O resultado da simulação do atendimento para a demanda de irrigação é exposto na Figura 19.

Figura 19. Retiradas para irrigação no reservatório Engenheiro Ávidos, Paraíba, Brasil

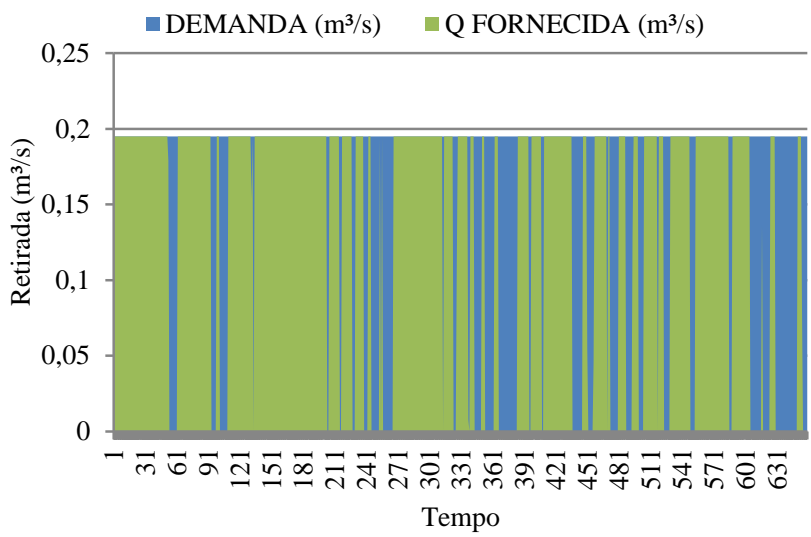

Como se pode perceber, a parcela demandada para a irrigação passa a apresentar muitas falhas, ou seja, não foi atendida com sucesso. Para a confiabilidade, o cálculo apresentou um valor de 70, 91\%. Difere da primeira simulação, que obteve falhas em quantidade bem menor, e por isso apresentou uma confiabilidade de atendimento relevantemente maior.

\section{Reservatório São Gonçalo}

Os resultados do reservatório São Gonçalo, obtidos através da simulação com demandas estimadas para o futuro. Como mostra a Figura 20, esse cenário apresenta mudanças relevantes no comportamento do reservatório.

Figura 20. Comportamento do volume armazenado do reservatório São Gonçalo, Paraíba, Brasil

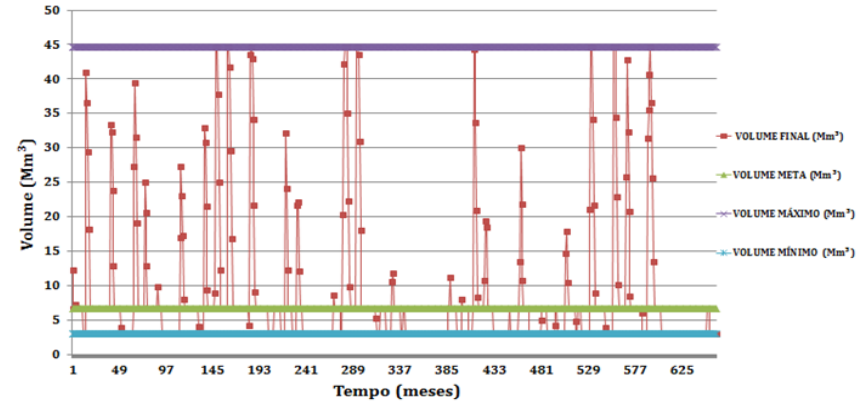


Para esse cenário, o reservatório passa a ter muitos episódios de volumes abaixo da meta, que se mantêm com ocorrências constantes em todo o período simulado, chega a operar com volume mínimo em vários meses. Em poucas ocasiões seu volume final alcança o volume total, e como o semiárido apresenta chuvas concentradas em poucos meses, a tendência é o déficit hídrico.

Em relação às demandas do reservatório São Gonçalo, em virtude do que foi relatado no item anterior, as diferenças foram bem acentuadas. A Figura 21 a seguir representa o atendimento à demanda para abastecimento

Figura 21. Retiradas para o abastecimento no reservatório São Gonçalo, Paraíba, Brasil

$$
\text { - DEMANDA }\left(\mathrm{m}^{3} / \mathrm{s}\right) \quad \mathrm{Q} \text { FORNECIDA }\left(\mathrm{m}^{3} / \mathrm{s}\right)
$$

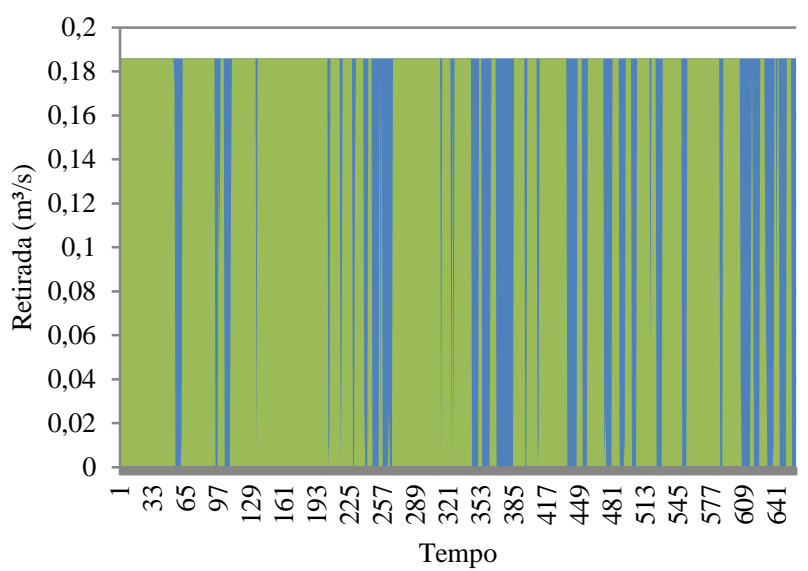

Como se pode observar, o atendimento às retiradas para abastecer a população dos dois municípios sofre grandes alterações. A confiabilidade apresentada para esse cenário foi de $74,70 \%$, valor muito abaixo do que o apresentado na primeira simulação. O reservatório não foi capaz de satisfazer a demanda em todos os meses, o que é evidenciado pelo grande número de falhas em diversos meses.

Esse mesmo fato ocorre para as retiradas com fins de suprir as necessidades dos animais, como é exposto na Figura 22, que representa a demanda dessedentação animal.

Figura 22. Retiradas para dessedentação animal no reservatório São Gonçalo, Paraíba, Brasil

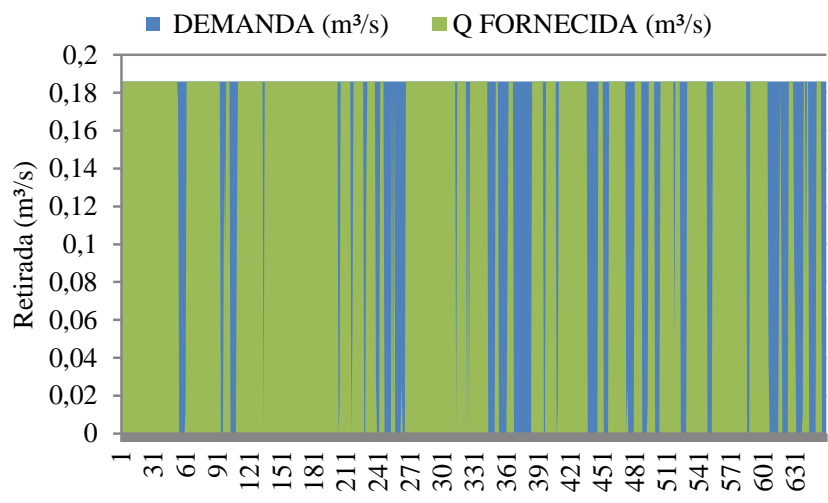

Tempo (meses)

O cálculo da confiabilidade para a demanda dessedentação animal indicou uma confiança de atendimento de $72,88 \%$, bastante distinta da primeira simulação, no qual esse percentual foi de $90,45 \%$.
Para a indústria, o resultado da simulação é exposto na Figura 23. A confiabilidade para o atendimento das retiradas da demanda industrial foi calculada em torno de $62,73 \%$.

Figura 23. Retiradas para a indústria no reservatório São Gonçalo, Paraíba, Brasil

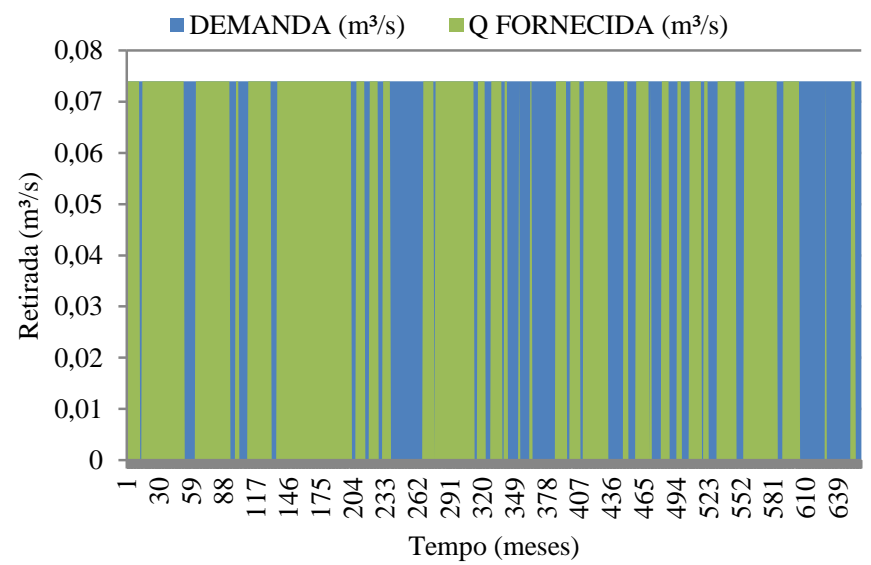

As falhas ocorrem com mais frequência, em muitos meses. Essa demanda não consegue ser atendida em muitos momentos nesse cenário.

A irrigação, que para este cenário futuro contou o aumento da demanda de $2,172\left(\mathrm{~m}^{3} / \mathrm{s}\right)$ para $4,248\left(\mathrm{~m}^{3} / \mathrm{s}\right)$, ou seja, quase dobrou o valor de retirada, e passou a apresentar a seguinte situação, de acordo com a simulação realizada.

Figura 24. Retiradas para irrigação no reservatório São Gonçalo, Paraíba, Brasil

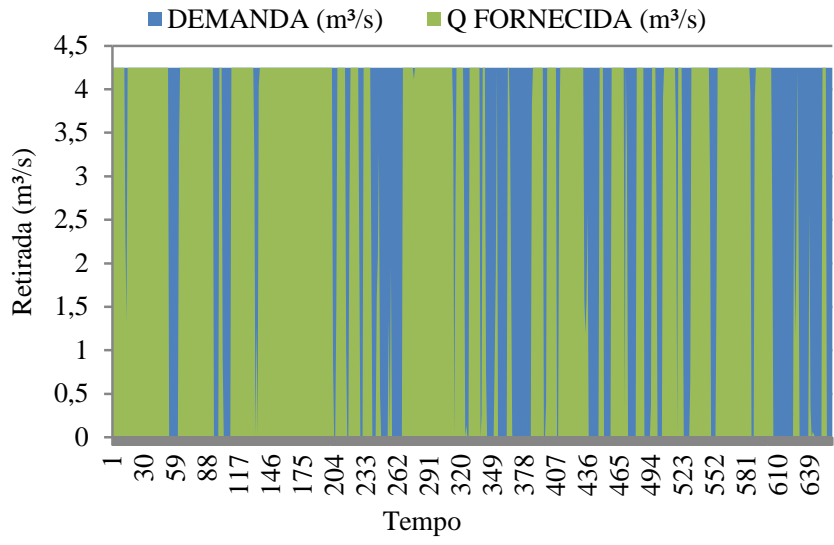

As falhas ao atendimento, antes sinalizadas em poucos meses, passam a estar presentes constantemente, ao longo de todo o período analisado. Já a confiabilidade de atendimento para este cenário foi de $61,79 \%$, uma grande queda na eficiência do atendimento a demanda de irrigação, no qual a confiabilidade para um cenário com retirada menor era de $89,3 \%$. Ou seja, para uma demanda maior, o reservatório não será capaz de suprir uma quantidade de água suficiente pra essa atividade.

\section{CONCLUSÕES}

A simulação da série histórica de 1962 a 2016, os dois reservatórios, na maioria dos meses, o volume meta foi respeitado, e devido às vazões mais acentuadas provenientes de períodos de chuvas mais abundantes, volume máximo foi alcançado. Ocorreram períodos em que a capacidade dos reservatórios chegou ao volume mínimo, em detrimento das 
poucas chuvas, que se tornaram mais presentes nos últimos anos, fazendo com que esses reservatórios ainda estejam, até o presente momento, longe de atingir sua capacidade máxima de armazenamento de água.

As demandas dos dois reservatórios, o comportamento foi similar, o abastecimento humano e dessedentação animal apresentaram confiabilidade um pouco acima dos $90 \%$, para a irrigação de culturas e indústria, o número de falhas no atendimento foi maior, em virtude da prioridade de cada uma, a confiabilidade ficou em torno de $89 \%$ e $88 \%$, respectivamente.

No cenário futuro, os reservatórios em poucos momentos chegaram ao seu volume máximo, para os mesmos períodos chuvosos e de estiagem, e por muitos meses operaram com seu volume mínimo, não conseguindo atender ao requerimento operacional do volume meta.

\section{REFERÊNCIAS}

ANA. Agência Nacional de Águas. Disponibilidade e demandas de Recursos Hídricos No Brasil. Cadernos de Recursos Hídricos. 2005. Disponível em: <http://www.ana.gov.br> Acesso em: 04 mar 2016.

ACQUANET - Modelo para alocação de água em sistemas complexos de recursos hídricos - Manual do Usuário (2013). Escola Politécnica da Universidade de São Paulo Departamento de Engenharia Hidráulica e Sanitária Laboratório de Sistemas de Suporte a Decisões (LabSid). São Paulo. 72p.

ANDRADE, P. R. S. de. Estudo para alocação ótima das águas de um sistema de reservatórios em série e em paralelo, para usos e objetivos múltiplos, na bacia do rio Capibaribe, PE. [TESE]. Campina Grande, 2006.

BRASIL. Lei $n^{\circ}$ 9.433. Política Nacional dos Recursos Hídricos. Brasília: Secretaria dos Recursos Hídricos, Ministério do Meio Ambiente, dos Recursos Hídricos e da Amazônia Legal. 1997.

BRASIL. Governo do Estado da Paraíba. Secretaria de Estado da Ciência e Tecnologia e do Meio Ambiente - SECTMA.
Agência Executiva de Gestão de Águas do Estado da Paraíba, AESA. Volumes dos Açudes. Disponível em: $<$ http://site2.aesa.pb.gov.br/aesa/volumesAcudes.do?metodo= preparaUltimosVolumesPorMunicipio> Acesso em: 16 out 2016.

FARIAS, S. R. A. Operação Integrada dos Reservatórios Engenheiro Ávidos e São Gonçalo. Dissertação apresentada ao curso de pós-graduação em Engenharia Civil e Ambiental, na área de Engenharia de Recursos Hídricos (2004).

FEITOSA, A. P. Otimização do uso das águas da barragem Santa Cruz-RN. [DISSERTAÇÃO]. Universidade Federal Do Rio Grande Do Norte. Natal, 2013.

MAIA, A. G. As consequências do assoreamento na peração de reservatórios formados por barragens / Adelena Gonçalves Maia. EESC- USP-São Carlos, 2008.

PARAÍBA. [Estado]. LEI N. ${ }^{\circ}$ 6.308, DE 02 DE JULHO DE 1996. Institui a Política Estadual de Recurso. 1996.

UNSGAB. Conselho de Assessoramento ao Secretário-Geral da ONU para Assuntos de Água e Saneamento. A Jornada do UNSGAB.

Disponível em:<http://arquivos.ana.gov.br/imprensa/arquivos/Relatorio_ Acesso_Agua.PDF> Acesso em: 22 mar 2016.

VIEIRA, A. S., Um Modelo de Simulação Via Programação Linear Sequencial, para Sistema de Recursos Hídricos. Campina Grande: UFCG - Pós-graduação em Engenharia Civil e Ambiental. 118p. Dissertação de Mestrado. (2007).

VIEIRA, A. S. Modelo de simulação quali-quantitativo multiobjetivo para o planejamento integrado dos sistemas de recursos hídricos / Allan Sarmento Vieira. Tese de Doutorado - Campina Grande, 2011.

SANTOS, V. da S. Modelo de otimização quali quantitativo multiobjetivo para o planejamento dos recursos hídricos superficiais, com aplicação à Bacia do Rio Paraíba - Tese de Doutorado. Campina Grande, 2011. 170 p. 